\title{
Three-dimensional thermomechanical converting of CTMP substrates: effect of bio-based strengthening agents and new mineral filling concept
}

\author{
Teija Laukala (i) - Sami-Seppo Ovaska (D) Ninja Kerttula $\cdot$ Kaj Backfolk
}

Received: 2 January 2021 / Accepted: 10 August 2021 / Published online: 25 August 2021

(C) The Author(s) 2021

\begin{abstract}
The effects of bio-based strengthening agents and mineral filling procedure on the 3D elongation of chemi-thermomechanical pulp (CTMP) handsheets with and without mineral (PCC) filling have been investigated. The $3 \mathrm{D}$ elongation was measured using a press-forming machine equipped with a special converting tool. The strength of the handsheets was altered using either cationic starch or microfibrillated cellulose. Precipitated calcium carbonate (PCC) was added to the furnish either as a slurry or by precipitation of nano-sized PCC onto and into the CTMP fibre. The 3D elongation of unfilled sheets was increased by the dry-strengthening agents, but no evidence on the theorised positive effect of mineral fill on 3D elongation was seen in either filling method. The performance of the strengthening agent depended on whether the PCC was as slurry or as a precipitated PCC-CTMP. The starch was more effective with PCC-CTMP than when the PCC was added
\end{abstract}

Supplementary Information The online version contains supplementary material available at https://doi.org/10.1007/ s10570-021-04139-4.

T. Laukala $(\bowtie) \cdot$ N. Kerttula

Packaging Technology of LUT School of Energy

Systems, Lappeenranta-Lahti University of Technology,

P.O. Box 20, 53850 Lappeenranta, Finland

e-mail: teija.laukala@lut.fi

S.-S. Ovaska · K. Backfolk

Stora Enso Oyj, Research Center Imatra, 55800 Imatra, Finland directly as a slurry to the furnish, whereas the opposite was observed with microfibrillated cellulose. The 3D elongation correlated positively with the tensile strength, bursting strength, tensile stiffness, elastic modulus and bending stiffness, even when the sheet composition was varied, but neither the strengthening agent nor the method of PCC addition affected the 3D elongation beyond what was expectable based on the tensile strength of the sheets. Finally, mechanisms affecting the properties that correlated with the 3D elongation are discussed.

Keywords 3D elongation - Press forming - PCC . CTMP · Composite filler

\section{Introduction}

Wood-fibre-based packaging materials offer a more sustainable alternative to fossil-based thermoplastic materials, but their use is hampered in many applications by their limited formability. Complex 3D shapes cannot be produced from 3D blanks or web substrates and the production of sealable trays and similar items faces difficulties due to the formation of wrinkles, cracks, holes or uneven rims. Recently, both the forming process (Groche et al. 2012; Leminen et al. 2015; Tanninen et al. 2015) and the paperboard substrate has gained interest with particular emphasis 
on its formability, the "ability of paper to be formed into 3D shapes without defects in appearance and functionality" as defined by Vishtal (2015). The mechanical properties that govern the formability of the substrate differ between the sliding blank and fixed blank processes, the latter of which emphasises extendable behaviour of the substrate (Vishtal 2015; Östlund 2017).

The extendable behaviour of paper and board is determined by the single fibre properties, fibre bonds, web structure, and any residual (drying) stresses (Östlund 2017). The relationship between the extensibility in $3 \mathrm{D}$ and the physical properties of board is however somewhat unclear, especially if post-treatments known to improve extensibility and their effect on the properties are considered. This, alongside related apparent contradictions connected to possible pre-treatments, is illustrated in Table 1 on behalf of some of the properties measured from paperboard on routine.

Laukala et al. (2019) reported that the characteristics of fracture in press-forming (fixed blank mode) depended on the pulp type used and they found that with CTMP pulp, fracture typically occurred in areas with a locally high fine content, while regions beneath the surface fines that contained longer fibres were

Table 1 Pre-treatments and some physical properties measured on routine, and their mentioned correlation with the 3D extensibility. All the 3D extensibility results reported were found to be relatively intact. Such a failure and rupture of the surface has been linked to the tensile failure of bonds (Page 1969; Seth 2005). Individual CTMP fibres are bulky, stiff and strong but they are known to have poorer bonding than kraft fibres. The characteristic behaviour of the bulky and stiff CTMP fibres supports the hypothesis that sheet failure in 3D may be especially due to weak interfibre bonding. Although CTMP has a lower extensibility than kraft pulp (Laukala et al. 2019), CTMP offers the bulk and stiffness needed in many packaging applications, and has environmental benefits (such as a higher yield and chlorine-free bleaching) over kraft pulp, while simultaneously being less prone to taste- and smell-related issues than mechanical pulps. These factors make CTMP-based boards interesting for 3D formation, especially if ways can be found to enhance the extensibility.

The relationship between the failure of fibres and the failure of bonds has been discussed by many authors, including Page (1969), who wrote: "as the point of failure is approached, more bonds fail in the rupture region and the remaining fibres take more of the sheet load, until the fibres lying in the direction of loading reach their rupture strain", and Retulainen (1996), who presented two formulae for tensile obtained using fixed blank mode type of stretching, except those marked with an asterisk $(*)$ were given in a more general context

\begin{tabular}{|c|c|c|}
\hline Property or pre-treatment & Effect on 3D extensibility & $\begin{array}{l}\text { Link to other properties affecting 3D } \\
\text { extensibility }\end{array}$ \\
\hline Elastic modulus & $\begin{array}{l}\text { High elastic modulus said to be detrimental }{ }^{* 1} \text { Positive } \\
\text { correlation observed experimentally }{ }^{2}\end{array}$ & \\
\hline Bending stiffness & Negative correlation observed experimentally $^{2}$ & $\begin{array}{l}\text { Linked with elastic modulus, high elastic } \\
\text { modulus increases bending stiffness }{ }^{3}\end{array}$ \\
\hline Tensile strength & $\begin{array}{l}\text { Typically, positive correlation reported }{ }^{4} \text {; higher } \\
\text { extensibility in the cross direction than the machine } \\
\text { direction }^{5}\end{array}$ & $\begin{array}{l}\text { Lower tensile index in the cross } \\
\text { direction than the machine direction }\end{array}$ \\
\hline $\begin{array}{l}\text { Compaction treatment, } \\
\text { spraying with selected } \\
\text { polymer(s) }\end{array}$ & Positive correlation observed experimentally ${ }^{4}$ & $\begin{array}{l}\text { Decreasing tensile stiffness }{ }^{4} \text {, } \\
\text { compaction decreases tensile }^{5,6} \text { strength }^{5,6}\end{array}$ \\
\hline $\begin{array}{l}\text { Increased moisture and } \\
\text { temperature (in } \\
\text { thermoforming) }\end{array}$ & Positive correlation reported ${ }^{* 1}$ & Reduction in elastic modulus ${ }^{7}$ \\
\hline $\begin{array}{l}\text { Deformation and } \\
\text { microcompression of fibres }\end{array}$ & Improvement in extensibility ${ }^{4}$ & Decreased elastic modulus ${ }^{8,9,10}$ \\
\hline
\end{tabular}

${ }^{1}$ Kajanto (2003), ${ }^{2}$ Laukala et al. (2019), ${ }^{3}$ Kajanto (1998), ${ }^{4}$ Vishtal (2015), ${ }^{5}$ Vishtal and Retulainen (2014a, b), ${ }^{6}$ Ihrman and Öhrn (1965), ${ }^{7}$ Salmén (1993), ${ }^{8}$ Page et al. (1979), ${ }^{9}$ Page and Seth (1980a), and ${ }^{10}$ Page and Seth (1980b) 
strength: one for sheets with poor bonding and thus few fibre breaks, and another for sheets in which a more significant amount of fibre breaks also take place. These formulae suggest that tensile strength can be increased by increasing the fibre width and fibre length, the amount of fibres on a fracture line, the specific bond strength and relative bonded area and, if a significant amount of fibre breaks take place, the single fibre's strength.

Within the paper industry, the dry strength is commonly improved by beating the pulp and by using dry-strengthening agents. To prepare a substrate with good (3D) elongation, beating is of great importance since it promotes internal and external fibrillation and leads to an increase in fines content, which improves strength properties (Koskenhely 2008). Microcompressions and deformations that reduce straightness, the presence of which have been associated with increased 3D elongation (Vishtal 2015), may also be created (Koskenhely 2008). A side-effect of beating, however, is a reduction in bulk (Koskenhely 2008), which may not be desired. The literature proposes techniques for the bulk preservation of (chemi)thermomechanical pulps, for example, by the microfibrillated cellulose (MFC) addition (Jahangir and Olson, 2020). It was shown that replacement of low consistency refining by the addition of MFC resulted in greater mechanical strength and a higher bulk. In combination with recent improvements in MFC production and fibre engineering, MFC is thus an interesting candidate as an agent strengthening fibrebased, bulky, 3D-formable materials.

Alongside the strengthening agents, another type of material often added to papermaking are mineral fillers, such as calcium carbonate either as ground or precipitated (GCC or PCC, respectively), clay, calcium sulfate or even titanium dioxide (Hubbe and Gill 2016). The mineral fillers differ both chemically and physically, and the different fillers can be used to alter and fine-tune the end-product properties, but also to reduce costs, or both (Hubbe 2004; Koivunen et al. 2009; Hubbe and Gill 2016). The typical motivation for filler use is to increase brightness and opacity, but also to control the pore size and friction of the paper (Shen et al. 2009; Hubbe and Gill 2016). Although the fillers also bring in negative effects, such as losses in sheet strength properties due to debonding (Hubbe and Gill 2016; Krogerus 2007), some of the effects, such as those related to altered friction, may be of interest in the context of 3D forming. In general, a low friction coefficient is beneficial for 3D forming (Östlund 2017), and the friction coefficient between metal and the substrate have been reported to correlate with formability in the fixed blank process (Vishtal 2015). In deep drawing, the friction affects runnability and process reliability (Lenske et al. 2017).

The use of fillers has also been suggested to improve thermal conductivity of the sheets, which may facilitate plasticization of the sheet in the thermoforming press (Kajanto 2003). In some cases, a synergy between the mineral filler and a drystrengthening agents may result in a significant improvement of the paper strength (Lindström et al. 2005). Cationic starch is reported to have such an effect (Lindström et al. 2005), and numerous methods to improve calcium carbonate filler by starch-modification have been reported (He et al. 2016; Kuusisto and Maloney 2016; Li et al. 2016).

The purpose of this study was to further clarify the role of strengthening agents and mineral fillers in 3D formable structures made of CTMP sheets with controlled and confirmed composition in respect to the fibres, strengthening aids and fillers, but different physical properties. The relationship between the physical properties and the 3D elongation was studied, with an emphasis on the role of strengthening agents as bonding enhancers, and dosing strategies for adding the filler. The dosage of cationic starch or MFC was varied, and the PCC filler was added either by adding the PCC as a slurry or by using a novel filler-fibre composite (PCC-CTMP prepared using in-situ precipitation of PCC). The PCC mineral was thus either synthetised in a batch process and added to the furnish, or in the presence of CTMP to prepare a composite filler-denoted PCC-CTMP, where a large proportion of the nano-PCC particles nucleated and grew onto and into the CTMP fibres.

\section{Materials and methods}

A hardwood (birch) CTMP was provided as dry sheets by Stora Enso Kaukopää mill (Imatra, Finland). The microfibrillated cellulose was a wood-based grade (Celish KY100S, Daicel FineChem Ltd., Japan) obtained in a high solids content (ca. 25 wt-\%) material, which was diluted to $1 \mathrm{wt}-\%$ solids under 
high shear mixing conditions using a Diaf dissolver mixer.

Calcium oxide, $\mathrm{CaO}$, (Honeywell, purity $\geq 95 \%$ ) and $\mathrm{CO}_{2}$ gas (AGA, purity $\geq 99.8 \%$ ) were used to precipitate calcium carbonate. The cationic starch used was Raisamyl 50021 (Chemigate, cationised potato starch with degree of substitution 0.035 ). The starch was mixed in $60{ }^{\circ} \mathrm{C}$ water, which was heated to 95-98 ${ }^{\circ} \mathrm{C}$ and cooked for $30 \mathrm{~min}$ while stirring. The cooked starch was stored in a closed vessel in an oven at $65{ }^{\circ} \mathrm{C}$ and used within $24 \mathrm{~h}$ of cooking.

\section{Sample preparation}

The sample preparation is shown diagrammatically in Fig. 1, and the precipitation steps and handsheet preparation is further described from 2.1.1. to 2.1.3. For clarity, pulp mixtures and handsheets are referred to on the basis of their composition as indicated in Table 2.

The CTMP was prepared by disintegration of CTMP pulp sheets with a Valley beater according to the ISO 5264-1 standard. After the disintegration, a CTMP pulp deficient in fines was prepared by applying a washing procedure because it has been reported that PCC preferentially precipitates on the fine fibre surfaces (Silenius 2002). Ca. 8 L of CTMP pulp from the beater (consistency ca. $15.7 \mathrm{~g} / \mathrm{l}$ ) was placed on a vessel equipped with 200 mesh metal wire. Water and fines were allowed to drain under gravity through the wire while stirring, and tap water was added to maintain its furnish volume. Each of the eight batches was washed using ca. $16 \mathrm{~L}$ of water for each batch. After the fines removal, the batches were mixed together to homogenise the material before use.

\section{PCC-CTMP composite filler precipitation}

The PCC-CTMP was prepared by reaction of $\mathrm{Ca}(\mathrm{OH})_{2}$ and $\mathrm{CO}_{2}$ to precipitate calcium carbonate in the presence of CTMP fibres in a $10 \mathrm{~L}$, open-batch reactor. The reactor was equipped with a stirrer and a gas outlet at the bottom. The fibre consistency was $1.3 \mathrm{wt}-\%$. The depletion of $\mathrm{Ca}(\mathrm{OH})_{2}$ was determined by the decrease in $\mathrm{pH}$. The temperature at the beginning of the exothermic reaction was ca. $20^{\circ} \mathrm{C}$ and the reaction was allowed to proceed without any further temperature control. A total of three batches were prepared and mixed together to provide a homogeneous material.

The $\mathrm{Ca}(\mathrm{OH})_{2}$ used was prepared from calcium oxide by slaking in water with a $\mathrm{CaO}: \mathrm{H}_{2} \mathrm{O}$ ratio of $1: 9$ for four hours. The initial temperature was $40{ }^{\circ} \mathrm{C}$. The $\mathrm{Ca}(\mathrm{OH})_{2}$ slurry obtained was filtered through a metal wire $(63 \mu \mathrm{m}$ openings) to remove large aggregates before use.

\section{PCC precipitation}

The PCC filler used was a laboratory-prepared grade free from chemical additives such as dispersing agents. The PCC was synthetised from $\mathrm{Ca}(\mathrm{OH})_{2}$ and $\mathrm{CO}_{2}$ as described above, but a higher reaction temperature was used, $77 \pm 3{ }^{\circ} \mathrm{C}$, to control the particle morphology, and the batch size was $2000 \mathrm{~g}$ (before precipitation). The reactor was equipped with a stirrer and a heating or cooling jacket for temperature control. The $\mathrm{Ca}(\mathrm{OH})_{2}$ concentration in the batch was 22 wt-\% (prior to precipitation). After the precipitation, the PCC was allowed to rest in an open container overnight to allow any excess $\mathrm{CO}_{2}$ to leave the sample. The PCC was then stored on a rotating table to avoid sedimentation. The PCC obtained was spikey, i.e., an agglomerated cigar-shaped particles. An example can be seen in Fig.

\section{Handsheet preparation}

Handsheets were prepared according to the ISO 5269-1:2005 standard with the exceptions of

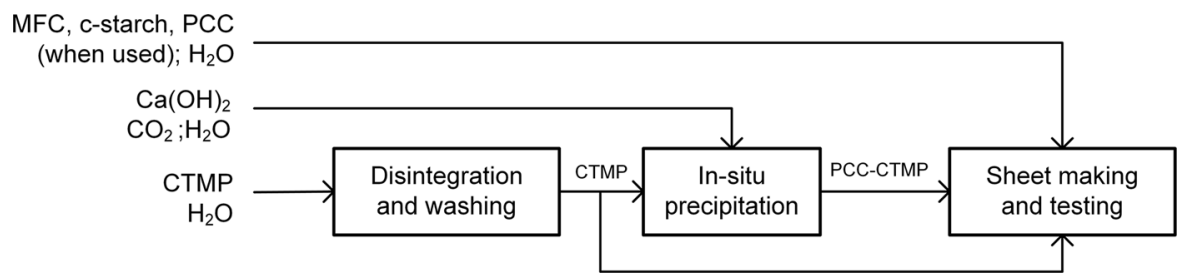

Fig. 1 Schematic diagram of the experiments 
Table 2 Nomenclature of samples

\begin{tabular}{ll}
\hline Sample identifier & Description \\
\hline CTMP & CTMP without added filler or strengthening agents \\
PCC-CTMP & PCC-CTMP composite prepared via in-situ precipitation \\
PCC & The PCC filler, $\mathrm{CaCO}_{3}$ precipitated in laboratory \\
CTMP\&PCC & CTMP with PCC filler, the mineral added as a slurry. No strengthening agents used \\
CTMP\&PCC(CS) & CTMP with PCC filler added as a slurry plus cationic starch as a strengthening agent \\
CTMP\&PCC(MFC) & CTMP with PCC filler added as a slurry. Microfibrillated cellulose as a strengthening agent \\
CTMP\&PCC-CTMP & PCC-CTMP filled CTMP sheet, or pulp mixture. No strengthening agents used \\
CTMP\&PCC-CTMP(CS) & PCC-CTMP filled CTMP sheet, or pulp mixture. Cationic starch as a strengthening agent \\
CTMP\&PCC-CTMP(MFC) & PCC-CTMP filled CTMP sheet, or pulp mixture. Microfibrillated cellulose as a strengthening agent
\end{tabular}

grammage (190 gsm) and drying, done using a drying drum (Lorentzen and Wettre) with a surface temperature of ca. $60{ }^{\circ} \mathrm{C}$ to allow shrinkage. The sheets prepared and their compositions are presented in Table 3.

The sheet composition was controlled gravimetrically. CTMP and PCC-CTMP (when used) were mixed in pre-determined ratios, and MFC and PCC were added to the pulp mixture until the targeted sheet weight was reached. Starch was added assuming $100 \%$ retention.

\section{Methods of analysis}

\section{Fibre analysis}

The samples were MFC, PCC-CTMP, PCC and the pulp mixtures used in handsheet preparation were analysed using the L\&W Fiber Tester (Lorentzen and Wettre, Kista, Sweden)diluted using approximately $0.1 \mathrm{~g}$ fibres to obtain $100 \mathrm{ml}$ of fibre suspension. The fibre length, fibre width, shape factor, amount of fines, mean kink angle, kinks per mm, kinks per fibre and kink index were then recorded. The results are lengthweighted.

\section{Handsheet testing}

The handsheets were tested according to the ISO 534 (density, thickness and bulk), ISO 5636-3 (Bendtsen porosity), ISO 8791-2 (Bendtsen roughness), ISO 287 (moisture content 50\% RH and 80\% RH), ISO 1924-3 (tensile strength, tensile stiffness, and elastic modulus), ISO 1974 (tearing resistance), ISO 2759 (bursting strength) and ISO 536 (grammage) standards. SCANP 92 was used for formation and specific formation, and bending stiffness $\left(5^{\circ}\right)$ was measured using DIN 53121. The measurements were made at $23{ }^{\circ} \mathrm{C}$ and $50 \% \mathrm{RH}$ using conditioned sheets. The amount of starch in the handsheets was measured using the Tappi standard T 419 om-04.

\section{Scanning electron microscopy}

FE-SEM imaging was conducted on cross section samples using an FEI Nova NanoSEM 450 field emission scanning electron microscope (FE-SEM) equipped with a Schottky-type emitter. The microscope was operated in a low vacuum mode using a Gaseous Analytical Detector (GAD) and a field-free final lens mode. The detected signal consisted of backscattered electrons (BSE). The chamber pressure was set to $70 \mathrm{~Pa}$ using water vapor from a built-in reservoir. The working distance was set to $5.0 \mathrm{~mm}$ and the acceleration voltage to $5.0 \mathrm{kV}$. Some images were obtained by mapping and stitching individual FE-SEM images with in-built automated image acquisition software, FEI MAPS 2.0.

Prior to FE-SEM imaging, the cross-section samples were prepared using a broad ion beam (BIB) cross section cutter (Hitachi IM4000) with a beam current of $120 \mu \mathrm{A}, 3 \mathrm{kV}$ acceleration voltage, $1.5 \mathrm{kV}$ discharge voltage and $400 \mu \mathrm{A}$ discharge current. The argon (Ar) gas flow was $0.08 \mathrm{ml} / \mathrm{min}$ and $\mathrm{Ar}$ ions hit the wire side first. A cover glass was placed between the sample and the mask. 
Table 3 The handsheets designations and their compositions. The ash, starch and moisture contents were measured using the handsheets, but the MFC content is given as the targeted, gravimetrically controlled dose

\begin{tabular}{|c|c|c|c|c|c|c|}
\hline Ident & Sheet type & $\begin{array}{l}\text { Ash content, } \\
525 \pm 25^{\circ} \mathrm{C}[\%]\end{array}$ & $\begin{array}{l}\text { MFC, targeted dose } \\
{[\%]}\end{array}$ & $\begin{array}{l}\text { Starch } \\
{[\%]}\end{array}$ & $\begin{array}{l}\text { Moisture, } 50 \% \text { rh } \\
{[\%]}\end{array}$ & $\begin{array}{l}\text { Moisture, } 80 \% \text { rh } \\
{[\%]}\end{array}$ \\
\hline 1 & CTMP & 0.7 & - & - & 7.8 & 12.0 \\
\hline 2 & СТMP\&PCC-СТMP & 3.8 & - & - & 7.4 & 12.3 \\
\hline 3 & CTMP\&PCC-CTMP & 12.3 & - & - & 6.8 & 11.1 \\
\hline 4 & CTMP\&PCC-CTMP & 15.4 & - & - & 6.4 & 10.9 \\
\hline 5 & CTMP\&PCC(MFC) & 8.8 & 3.6 & - & 6.7 & 11.6 \\
\hline 6 & CTMP\&PCC(MFC) & 25.0 & 3.6 & - & 5.9 & 9.5 \\
\hline 7 & CTMP\&PCC(CS) & 8.5 & - & 1.0 & 7.5 & 11.8 \\
\hline 8 & CTMP\&PCC(CS) & 14.1 & - & 1.0 & 6.9 & 10.6 \\
\hline 9 & CTMP(MFC) & 0.7 & 1.6 & - & 8.2 & 11.1 \\
\hline 10 & CTMP(MFC) & 0.7 & 4.8 & - & 7.6 & 11.9 \\
\hline 11 & CTMP(MFC) & 9.0 & 1.6 & - & 7.4 & 11.6 \\
\hline 12 & $\begin{array}{l}\text { CTMP\&PCC- } \\
\text { CTMP(MFC) }\end{array}$ & 8.6 & 4.8 & - & 7.3 & 11.1 \\
\hline 13 & $\begin{array}{l}\text { CTMP\&PCC- } \\
\text { CTMP(MFC) }\end{array}$ & 15.3 & 1.6 & - & 6.4 & 11.1 \\
\hline 14 & $\begin{array}{l}\text { CTMP\&PCC- } \\
\text { CTMP(MFC) }\end{array}$ & 16.7 & 4.8 & - & 6.6 & 11.0 \\
\hline 15 & CTMP(CS) & 0.7 & - & 0.8 & 7.9 & 12.4 \\
\hline 16 & CTMP(CS) & 0.7 & - & 0.9 & 7.8 & 12.5 \\
\hline 17 & $\begin{array}{l}\text { CTMP\&PCC- } \\
\text { CTMP(CS) }\end{array}$ & 7.7 & - & 0.7 & 7.3 & 12.0 \\
\hline 18 & $\begin{array}{l}\text { CTMP\&PCC- } \\
\text { CTMP(CS) }\end{array}$ & 7.6 & - & 1.0 & 7.3 & 12.5 \\
\hline 19 & $\begin{array}{l}\text { CTMP\&PCC- } \\
\text { CTMP(CS) }\end{array}$ & 17.7 & - & 0.8 & 6.5 & 10.6 \\
\hline 20 & $\begin{array}{l}\text { CTMP\&PCC- } \\
\text { CTMP(CS) }\end{array}$ & 15.8 & - & 1.2 & 6.9 & 11.1 \\
\hline
\end{tabular}

\section{Press-forming trials}

To determine the 3D elongation of the sheets, samples were press-formed using the LUT Packaging Line using a MiniMould tool (Fig. 2) developed to test the formability of experimental materials such as handsheets. The method involves press-forming of the substrate using a fixed blank mode, with an unheated male tool and a heated female tool. Female tool temperatures of 120 and $160{ }^{\circ} \mathrm{C}$ were used. Before forming, the sheets were conditioned at $23{ }^{\circ} \mathrm{C}$ and $80 \% \mathrm{RH}$. The conditioning was chosen based on a previous suggestion (moisture level of the formed sheet approximately 9-11\%) by Tanninen et al. (2017a). 3D elongation of a material was determined to be the maximum forming depth without ruptures detected visually. The equipment and methods are described in more detail by Tanninen et al. (2017b).

The $3 \mathrm{D}$ elongation is given as the average of the measured elongation at the two temperatures, as the $3 \mathrm{D}$ elongation rarely differed between the different temperatures.

\section{Results}

Fibre characterization

Results of the fibre characterisation are shown in Fig. 3. The tabulated values are available in Online Resource 1. The CTMP showed long $(1.57 \mathrm{~mm})$ and wide $(41.4 \mu \mathrm{m})$ fibres. The fines content after washing 


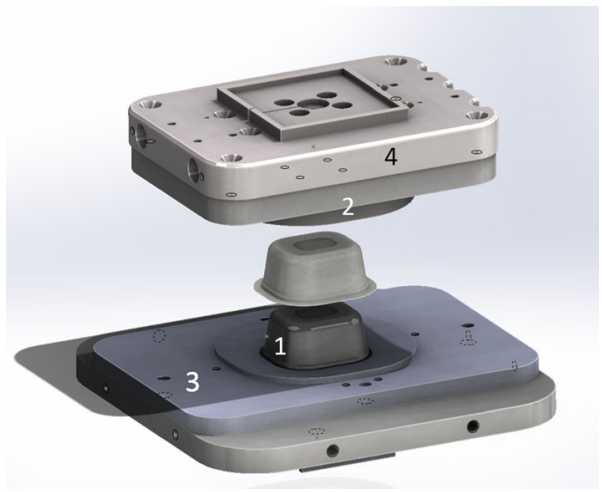

Fig. 2 Press-forming tool set: (1) the male mould, (2) the female mould, (3) the rim tool and (4) the heating unit

was only $10.2 \%$, and the fibres were quite straight with a shape factor of $89.5 \%$.

When the PCC-CTMP was prepared, the shape factor, the fibre width and the amount of fines were slightly increased, whereas the fibre length and the kinkiness slightly decreased. The most significant change was the increase in fines content, which was associated primarily with an increase in the size of the fine particle fraction due to the precipitation of PCC on CTMP fines, bringing the smaller fines to a size large enough to be detected by the fibre analyser.

It has been suggested that the PCC precipitates primarily on the cellulosic fines because the surface area of fines is much greater than that of the larger fibres (Silenius 2002). PCC attached to the surfaces of larger fibres should also increase the fibre width, and a small increase $(0.3 \mu \mathrm{m})$ was observed. The increase was in good agreement with the mineral layer thickness (ca. $150 \mathrm{~nm}$ ) in the SEM images (Fig. 8), although the detected change was smaller than the sensitivity of the fibre analyser indicated by the manufacturer.

The fibre analyser had a limited capacity to recognise small fibre fractions and fillers, but samples of the PCC filler and MFC were measured to observe how the materials were detected. The PCC was poorly detected, and the MFC was seen as short and thin fibres with a low shape factor. The amount of fines was high, $110 \%$ related to the amount of fibres with a length greater than $0.2 \mathrm{~mm}$. The mean kink angle, kink index and kinks/mm were higher than those of CTMP or PCC-CTMP, but the number of kinks/fibre was lower.

When samples of the pulp mixture were taken during handsheet preparation, the fibre properties were found to follow the furnish composition in a logical manner. For example, when MFC was added to the mixture, the fibre width and fibre length decreased slightly and the fines content increased.

Sheet composition and properties

The handsheets and their compositions are listed in Table 3, and the physical properties of the handsheets are given in Table 4. The effects of the reinforcing agents and of increasing ash content are summarised in Table 5. The data plots are available in the Online Resource 1. The trends observed in the handsheet properties were in general as expected, i.e. mineral filler decreased strength and bulk, and the strengthening agents increased strength but reduced bulk. Some exceptions and differences were, however, observed between CTMP\&PCC and CTMP\&PCC-CTMP sheets, and between the strengthening agents.

With increasing ash content, the CTMP\&PCCCTMP(CS) showed a slight increase in tensile stiffness and elastic modulus, but a negative effect on bulk and strength. The difference in strength properties between CTMP\&PCC-CTMP(CS) and CTMP\&PCC(CS) sheets was not explained by the presence of starch, as the CTMP\&PCC(CS) sheets had $1.0 \%$ starch and the CTMP\&PCC-CTMP(CS) contained from 0.7 to $1.2 \%$ starch. Starch was therefore more effective as a strengthening agent for CTMP\&PCC-CTMP than for CTMP\&PCC. The situation was the opposite when MFC was used as a strengthening agent. At a given ash content, CTMP\&PCC-CTMP(MFC) had a lower strength than CTMP\&PCC(MFC).

The observed difference in strength was attributed to the decreased bonding of MFC due to a loss of PCCfree surface area in both PCC-CTMP and MFC (see Fig. $8 \mathrm{c}$ and d), but also to a synergy between the starch and PCC-CTMP. These factors are discussed in more detail later.

The strengthening agents affected the specific formation of the sheets in a negative manner, but when PCC-CTMP was used instead of PCC, the negative effect was less obvious, and the specific formation was improved by an increase in ash content. The difference was not due to a difference in starch retention, since this was similar with both dosing strategies. 


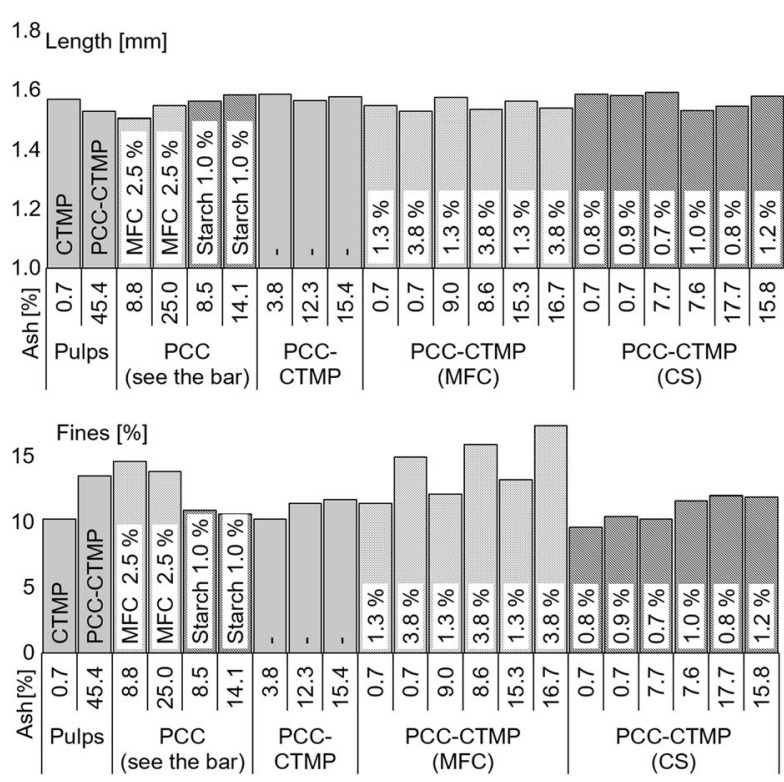

Fig. 3 Fibre characteristics of CTMP, PCC-CTMP and the mixtures used to make the handsheets. The $\mathrm{X}$-axis indicates ash content of the sheet obtained using the material and the filler type, i.e. whether PCC or PCC-CTMP was used. The amount of

The use of cationic starch appeared to increase the bulk of CTMP\&PCC(CS) and CTMP\&PCCCTMP(CS) sheets in comparison to that of the CTMP and CTMP\&PCC-CTMP sheets. This was probably due to the rougher sheet surface, as the thickness was measured using a single sheet. The roughness values exceeded the equipment maximum, but a greater roughness was supported by the poorer formation and cross-section SEM images (Fig. 7), which suggested that the fibres were packed more densely. The sheets were thinner when the starch was used, despite the similar grammage. The bulk was decreased with the addition of MFC.

3D elongation tests and the relationship between 3D elongation and sheet properties

According to Vishtal (2015), sheet extensibility and tensile strength govern formability (i.e. depth of shape) in the case of fixed blank forming. In the present case, sheet extensibility was measured as 3D elongation using a fixed blank mode. In the MiniMould system used, the 3D elongation indicated by the maximum depth without rupture is known to correspond to the $3 \mathrm{D}$ elongation defined based on the surface area increase of the elongating part of the
45

Width [mm]
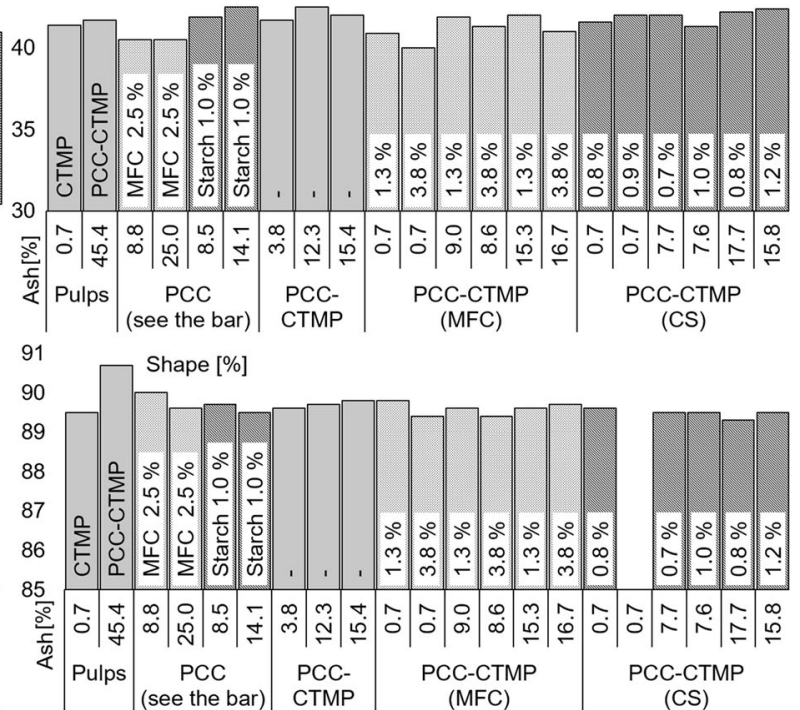

(CS)

reinforcing agent (or the pulp type) is indicated inside each bar. The amount of starch was measured after the sheets had been prepared, whereas the MFC amount is the targeted amount

substrate during forming. A more detailed description of the 3D elongation is given by Tanninen et al. (2017b).

In the present case, the reference CTMP sheets had a 3D elongation of $2 \mathrm{~mm}$, which in the system used corresponded to a value of $0.5 \%$. For comparison, the system has previously yielded a $3 \mathrm{D}$ elongation of $2 \%$ for the $190 \mathrm{~g} / \mathrm{m}^{2}$ commercial three-ply board used to prepare pressed trays, and $1.2 \%$ for CTMP sheets with a fines content of $11.7 \%$ (Laukala et al. 2019). The 3D elongation results for the handsheets are shown in Fig. 4 and tabulated in Table 4.

Neither dosing method of filler or strengthening aid was found to be superior for enhancing the 3D elongation. Their effect on sheet 3D elongation is described in 3.3.1 Effect of the strengthening agents and ash content. Correlation was found, however, for the $3 \mathrm{D}$ elongation with a set of physical properties of the sheets: a positive correlation between $3 \mathrm{D}$ elongation and bending stiffness, elastic modulus, tensile strength and stiffness and bursting strength within each series, with the exception of the elastic modulus and tensile stiffness in the case of CTMP\&PCCCTMP(CS). The correlations, described under 3.3.23D elongation: comparison of all the sheets, remained when no respect was paid to the sheet 


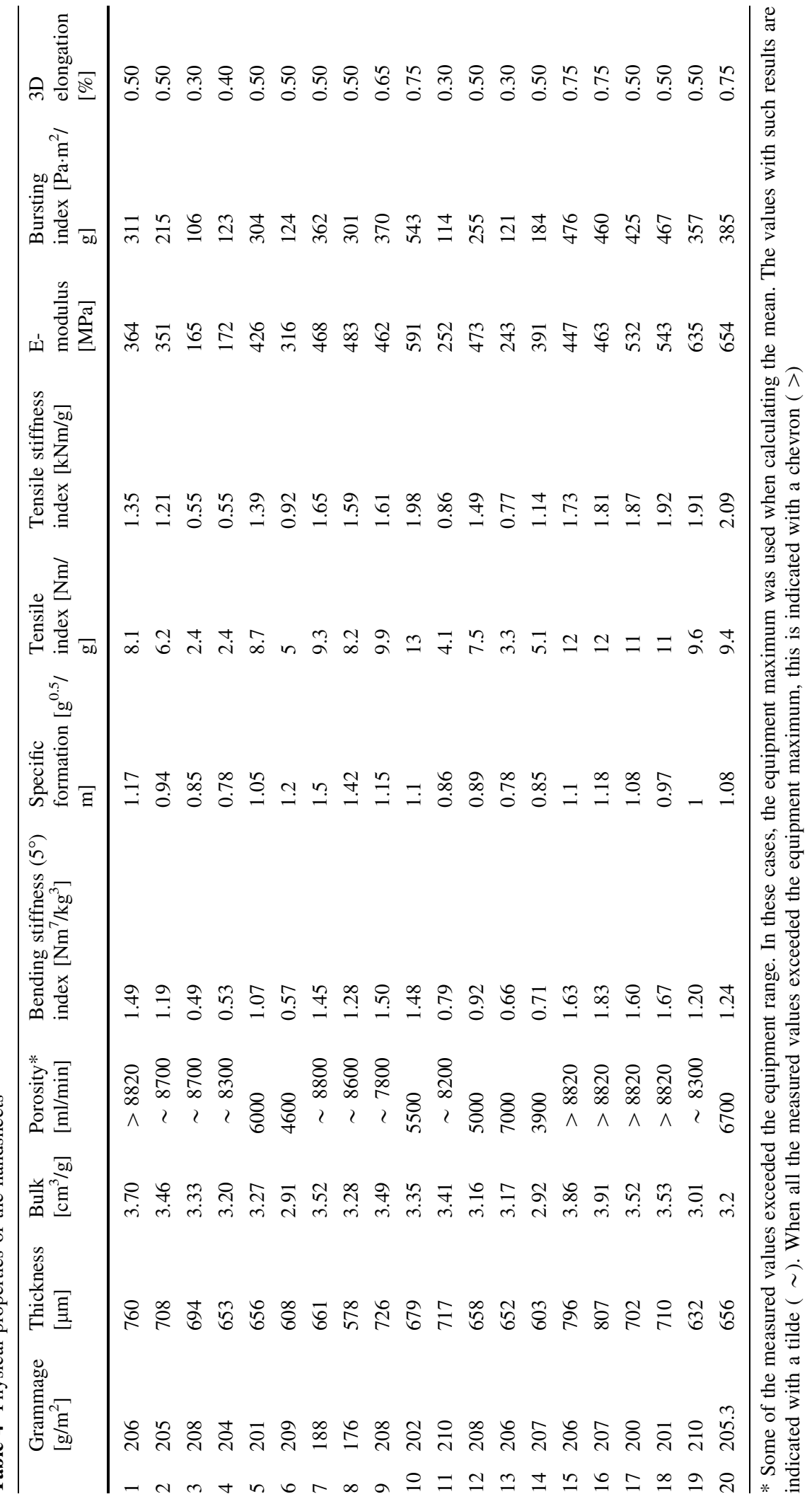


Table 5 Qualitative summary of the effects of the dry strengthening agents on the sheet properties with increasing ash content by ash type. Effect of the strengthening agents is given in comparison with the strengthening-agent-free PCC-CTMP series

\begin{tabular}{|c|c|c|c|}
\hline & $\begin{array}{l}\text { Filling } \\
\text { method }\end{array}$ & Effect of increasing ash and effect of MFC & Effect of increasing ash and effect of cationic Starch \\
\hline \multirow[t]{2}{*}{$\begin{array}{l}\text { Bending } \\
\text { stiffness }\end{array}$} & $\begin{array}{l}\text { PCC } \\
\text { slurry }\end{array}$ & $\begin{array}{l}\text { Filler decreased bending stiffness. The loss of bending } \\
\text { stiffness was slightly alleviated by the MFC }\end{array}$ & $\begin{array}{l}\text { Filler decreased bending stiffness. The loss slightly } \\
\text { alleviated by the starch }\end{array}$ \\
\hline & $\begin{array}{l}\text { PCC- } \\
\text { CTMP }\end{array}$ & See PCC slurry & $\begin{array}{l}\text { Filler decreased bending stiffness. The loss } \\
\text { alleviated by the starch more than in the case of } \\
\text { traditional dosing }\end{array}$ \\
\hline \multirow[t]{2}{*}{$\begin{array}{l}\text { Elastic } \\
\text { modulus }\end{array}$} & $\begin{array}{l}\text { PCC } \\
\text { slurry }\end{array}$ & $\begin{array}{l}\text { Filler decreased elastic modulus. Loss alleviated by } \\
\text { the MFC }\end{array}$ & $\begin{array}{l}\text { Effect of filler negligible, increase in elastic } \\
\text { modulus due to the starch }\end{array}$ \\
\hline & $\begin{array}{l}\text { PCC- } \\
\text { CTMP }\end{array}$ & See PCC slurry & $\begin{array}{l}\text { Filler increased elastic modulus, which was further } \\
\text { increased by the starch }\end{array}$ \\
\hline \multirow[t]{2}{*}{$\begin{array}{l}\text { Tensile } \\
\text { stiffness }\end{array}$} & $\begin{array}{l}\text { PCC } \\
\text { slurry }\end{array}$ & $\begin{array}{l}\text { Filler decreased tensile stiffness. Loss slightly } \\
\text { alleviated by the MFC }\end{array}$ & $\begin{array}{l}\text { Filler decreased tensile stiffness. Loss alleviated by } \\
\text { the starch }\end{array}$ \\
\hline & $\begin{array}{l}\text { PCC- } \\
\text { CTMP }\end{array}$ & See PCC slurry & $\begin{array}{l}\text { Filler increased tensile stiffness, which was further } \\
\text { increased by the starch }\end{array}$ \\
\hline \multirow[t]{2}{*}{$\begin{array}{l}\text { Tensile } \\
\text { strength }\end{array}$} & $\begin{array}{l}\text { PCC } \\
\text { slurry }\end{array}$ & $\begin{array}{l}\text { Filler decreased tensile strength. Loss alleviated by } \\
\text { the MFC }\end{array}$ & $\begin{array}{l}\text { Filler decreased tensile strength. Loss was alleviated } \\
\text { by the starch, but to a lesser degree than in the } \\
\text { case of PCC-CTMP }\end{array}$ \\
\hline & $\begin{array}{l}\text { PCC- } \\
\text { CTMP }\end{array}$ & $\begin{array}{l}\text { Filler decreased tensile strength. Loss was alleviated } \\
\text { by the MFC, but to a lesser degree than in the case of } \\
\text { traditional dosing }\end{array}$ & $\begin{array}{l}\text { Filler decreased tensile strength. Tensile strength } \\
\text { greatly improved by the starch }\end{array}$ \\
\hline \multirow[t]{2}{*}{$\begin{array}{l}\text { Bursting } \\
\text { strength }\end{array}$} & $\begin{array}{l}\text { PCC } \\
\text { slurry }\end{array}$ & $\begin{array}{l}\text { Filler decreased bursting strength. Loss alleviated by } \\
\text { the MFC }\end{array}$ & $\begin{array}{l}\text { Filler decreased bursting strength. The loss } \\
\text { alleviated by the starch }\end{array}$ \\
\hline & $\begin{array}{l}\text { PCC- } \\
\text { CTMP }\end{array}$ & See PCC slurry & $\begin{array}{l}\text { Filler decreased bursting strength. The loss greatly } \\
\text { alleviated by the starch }\end{array}$ \\
\hline \multirow[t]{2}{*}{ Formation } & $\begin{array}{l}\text { PCC } \\
\text { slurry }\end{array}$ & $\begin{array}{l}\text { Filler increased formation, MFC use increased } \\
\text { formation }\end{array}$ & $\begin{array}{l}\text { Decrease of formation with increasing ash, but great } \\
\text { increase of formation by the starch }\end{array}$ \\
\hline & $\begin{array}{l}\text { PCC- } \\
\text { CTMP }\end{array}$ & $\begin{array}{l}\text { Filler decreased formation, but an increase of } \\
\text { formation took place when MFC was used }\end{array}$ & $\begin{array}{l}\text { Decrease of formation with increasing ash, but an } \\
\text { increase of formation when the starch was used }\end{array}$ \\
\hline \multirow[t]{2}{*}{ Bulk } & $\begin{array}{l}\text { PCC } \\
\text { slurry }\end{array}$ & Decrease of bulk with increasing filler and MFC & $\begin{array}{l}\text { Decrease of bulk with increasing ash and by the } \\
\text { starch }\end{array}$ \\
\hline & $\begin{array}{l}\text { PCC- } \\
\text { CTMP }\end{array}$ & See PCC slurry & See PCC slurry \\
\hline
\end{tabular}

composition. The properties found to correlate with the $3 \mathrm{D}$ elongation also correlate themselves. This is further discussed under 4.2 3D elongation and the load-elongation curve. The other physical properties measured were not found to show a significant correlation with the 3D elongation, and no evidence on the effect of filling or strengthening aids, e.g., via altered friction of thermal conductivity was observed, beyond that of their effect on the physical properties of the sheets.

\section{Effect of the strengthening agents and ash content}

The strengthening agents increased the 3D elongation when no mineral filler was used. With increasing ash content, CTMP\&PCC, CTMP\&PCC(CS) and CTMP\&PCC(MFC) sheets showed the same 3D elongation behaviour as the CTMP sheet, although the chemical compositions and strength properties of the sheets were altered due to the filler and use of the strengthening agent. Even when the ash content reached $25 \%$, the $3 \mathrm{D}$ elongation of CTMP\&PCC(MFC), $25 \mathrm{~kg}_{\mathrm{MFC}} / \mathrm{t}$, was not less than that of the CTMP sheets. This appeared to be due 


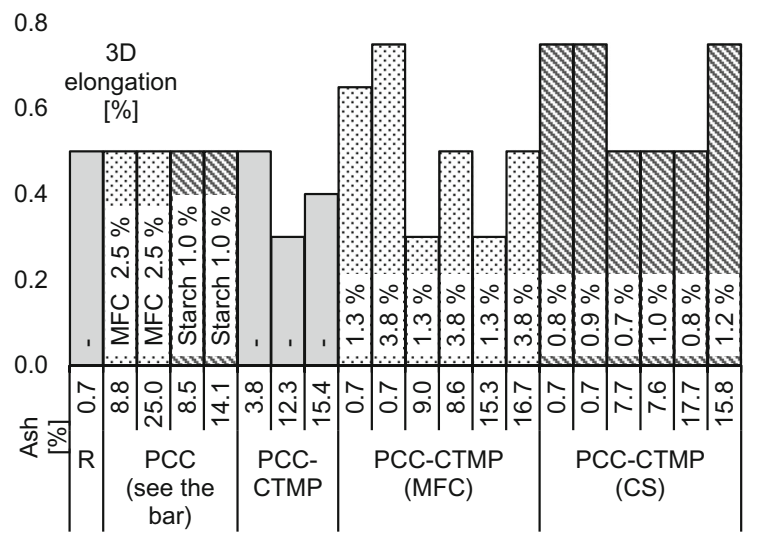

Fig. 4 Summary of the 3D elongation results. The $\mathrm{x}$-axis shows the dosing method of the PCC (i.e. whether PCC was added as a slurry or as PCC-CTMP), the bonding agent used, and the handsheet ash content $\left(525 \pm 25^{\circ} \mathrm{C}\right)$. The amount of bonding agent is indicated inside each bar. Reference $(R)$ was the CTMP sheet with neither the mineral filler nor the binder

primarily to the ability of the MFC to maintain the strength properties of the CTMP\&PCC(MFC) sheets. The tensile strength was similar to that of the CTMP\&PCC-CTMP(MFC) sheet with $16.7 \%$ ash and $38 \mathrm{~kg}_{\mathrm{MFC}} / \mathrm{t}$, and the $3 \mathrm{D}$ elongation of the sheets was mainly explained by their strength properties (see: 3.3.2 3D elongation: comparison of all the sheets).

Filling the sheet with PCC-CTMP without a strengthening agent decreased the 3D elongation of the sheets, see Fig. 4, but either MFC or starch restored the $3 \mathrm{D}$ elongation when a sufficiently large dose was used. However, when the sheets were filled with PCC-CTMP, the starch (12 kg/t and $15.8 \%$ ash) increased the 3D elongation above that of the reference, whereas MFC appeared detrimental for 3D elongation when the dose was low, as CTMP\&PCCCTMP(MFC) with $1.3 \mathrm{wt}-\%$ MFC gave a lower 3D elongation than the CTMP\&PCC-CTMP with a similar ash content. Starch was more effective for improving or maintaining the $3 \mathrm{D}$ elongation of the sheets than the MFC, especially when the filler was PCC-CTMP.

\section{$3 D$ elongation: comparison of all the sheets}

The 3D elongation is plotted against the tensile stiffness and the tensile strength in Figs. 5 and 6, respectively. A positive trend is evident in both cases, but the $\mathrm{R}^{2}$ values are low, possibly due to the limited resolution of the 3D elongation measurements, or perhaps variations in the properties.

There was no significant correlation between 3D elongation and ash content, but there was a negative correlation between ash content and bending stiffness probably due to the decrease in sheet thickness with increasing ash content. The lack of correlation between the ash content and the other properties was probably affected by the fact that the strengthening agents were able to compensate for the strength loss caused by the filler.

\section{Scanning electron microscopy}

SEM micrographs of cross-cut samples (Figs. 7 and 8) showed the differences between the samples depending on sample composition. The most obvious changes were between sheets filled with PCC or PCC-CTMP, which was evident based on the filler morphology, and the CTMP sheet, which did not contain PCC. In addition, a change in sample thicknesses was detected although the grammages were similar, especially when cationic starch was used, both for CTMP\&PCC(CS), in Fig. 7d, and CTMP\&PCCCTMP(CS), in Fig. 7e.

Figure 7 shows the two-sidedness of the nonformed sheets and particularly that the fillers were concentrated on the wire side, especially when the PCC filler was used (Fig. 7d). In the case of PCCCTMP (Fig. 7b, c and e), the PCC was more strongly attached on the fibres prior to the forming of the sheet,

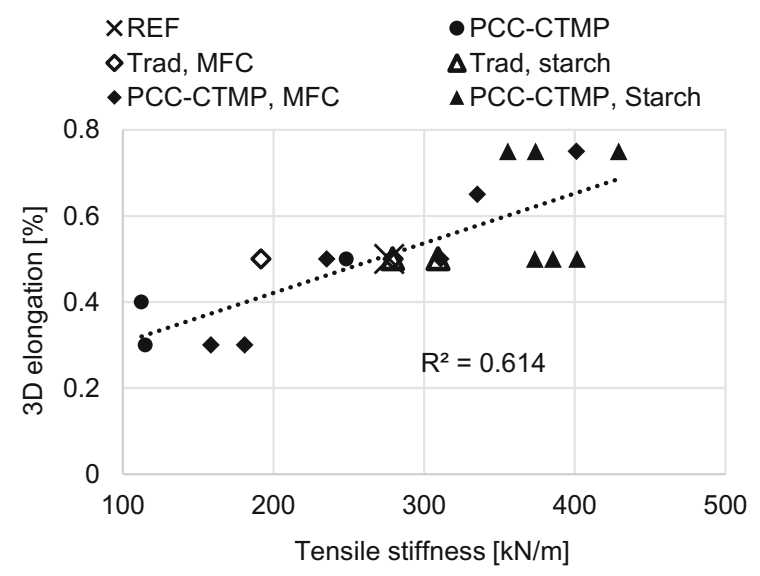

Fig. 5 The correlation of 3D elongation and tensile stiffness. Note that the resolution of $3 \mathrm{D}$ elongation results at the range of the measurements was $0.25 \%$. The results were given as an average after measuring in two forming temperatures 


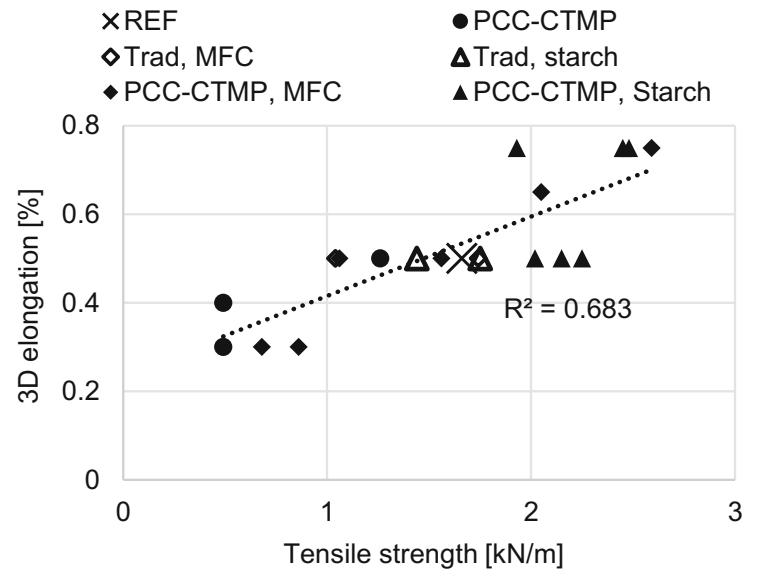

Fig. 6 The correlation of 3D elongation and tensile strength. Note that the resolution of 3D elongation results at the range of the measurements was $0.25 \%$. The results were given as an average after measuring at two different forming temperatures

and the mineral was also found inside the fibre lumens, where aggregates of nano-sized particles formed an uneven coating on the inner fibre surface, as shown in Fig. 8c. An example of a fibre with a more heavily filled lumen is shown in Fig. 8c

A small amount of loose fibrils were seen in the CTMP reference (Fig. 7a), but the amount increased when PCC-CTMP was added to the furnish (Fig. 7b). A comparison between covered and not covered fibrillary material is shown in Fig. 8 (the close-ups). When the sheets were filled with PCC (Figs. 7d and $8 \mathrm{~b}$ ), the mineral was seen to attach onto the fibrils, but much of the area of fibres and fibrils remained PCCfree, and use of starch decreased the amount of loose fibrils (Fig. 7d, it close-up and e). The micrographs suggest that the MFC was dispersed quite well, as no obvious MFC flocs are seen in the micrographs. Another detail of PCC-CTMP filled sheets was that when the starch was used as a strengthening agent, the PCC appeared to form bridges between fibres. An example of this is shown in Fig. 9.

\section{Discussion}

Despite the sheets being filled using two different dosing strategies, and the use of a strengthening aid, no evidence of the effect of filling or strengthening aids beyond that of their effect on the physical properties of the sheets was observed. The findings are discussed from two perspectives. First, the effects of sheet composition on their physical properties is covered under 4.1 Effect of mineral phase on sheet physical properties. Then, under 4.2 3D elongation and loadelongation curve, the discussion focuses on the $3 \mathrm{D}$ elongation and the physical properties for which the correlations were found. The relationships and origins of the properties are used to discuss the finding that the correlation for 3D elongation and the elastic modulus and/or tensile stiffness was positive for the CTMP despite the high elastic modulus usually being viewed as detrimental (Kajanto 2003).

Effect of mineral phase on sheet physical properties

The differences in fibre morphology between the PCCCTMP and CTMP pulps were insignificant and unlikely to explain the differences in sheet properties. The physical and chemical conditions of PCC-CTMP preparation were relatively mild, and a chemical change sufficient to significantly contribute to the physical properties was deemed unlikely. The differences in physical properties between the CTMP\&PCC and CTMP\&PCC-CTMP sheets were attributed to distribution of the mineral phase, resulting in disruption of the sheet bonding and possible interaction with the strengthening agent.

The PCC filler was of a high-bulking type known to reduce sheet strength due to the loss of inter-fibre bonding (Hubbe 2004), whereas the PCC-CTMP had a more even distribution of PCC on fibre surfaces and a large PCC surface area. The mineral in the PCCCTMP was expected to prevent direct contact between the cellulosic fibres and to reduce inter-fibre bonding. Such a loss of strength is known to take place when filler particles are small (Hubbe 2004), and the lower strength in the case of CTMP\&PCC-CTMP suggested that this was the case. The loss of strength remained when the amount of ash was subtracted from the grammage used in the calculation of the various indexes (fibre-weight based).

The ineffectivity of MFC as a strengthening agent was partially linked to its only moderate ability to increase the dry strength of mechanical pulp sheets (Kajanto and Kosonen 2012), but this does not explain why the MFC appeared to be more beneficial for PCC than PCC-CTMP-filled sheets, while the situation was the opposite with starch. The loose fibrils seen in the 

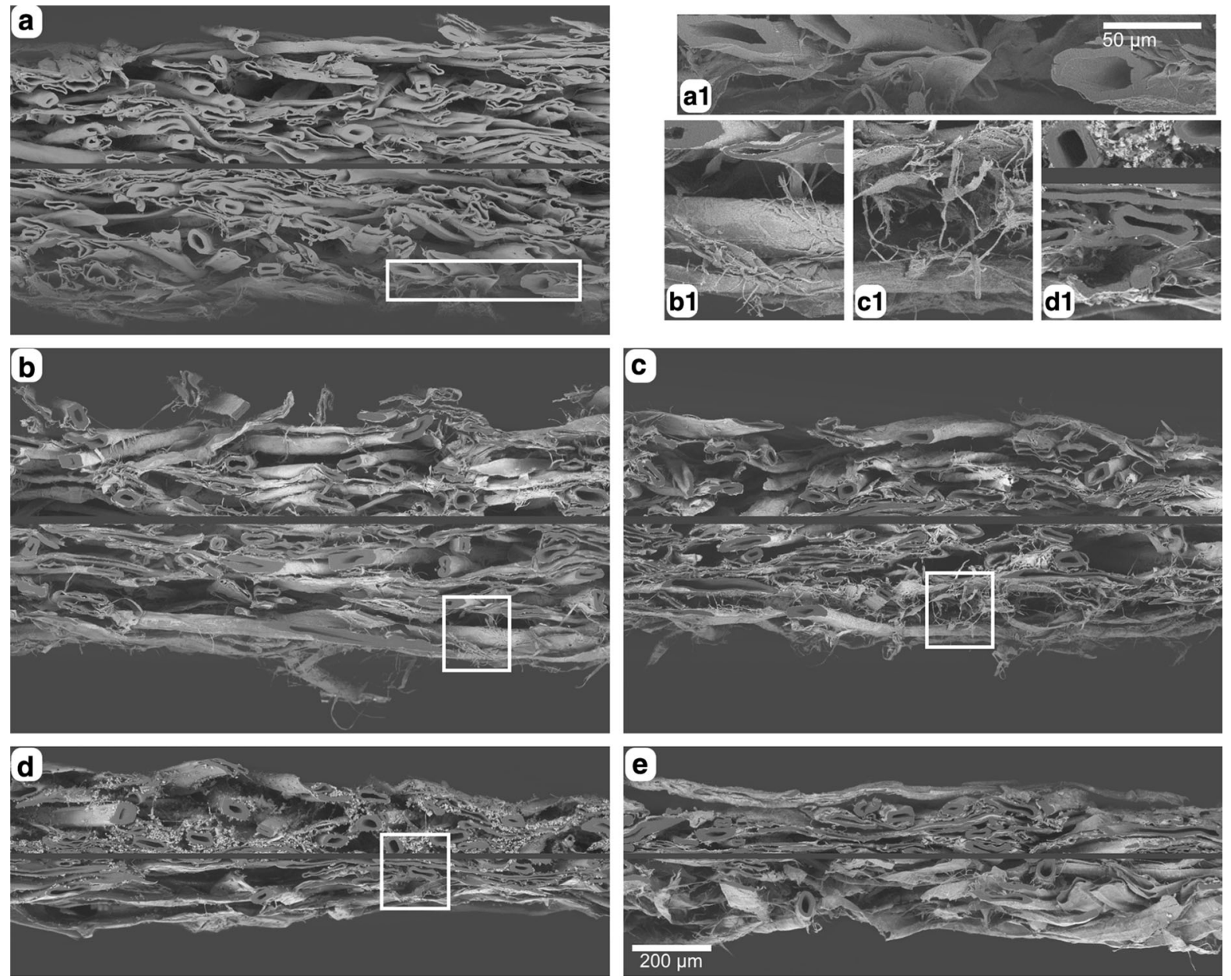

Fig. 7 SEM micrographs of the cross-section of samples: a CTMP: reference sample, b CTMP\&PCC-CTMP, without a strengthening agent, $\mathbf{c}$ CTMP\&PCC-CTMP(MFC), $13 \mathrm{~kg}_{\mathrm{MFC}} / \mathrm{t}$ d CTMP\&PCC(CS), $12 \mathrm{~kg}_{\mathrm{CS}} / \mathrm{t}$, and e CTMP\&PCC-CTMP(CS), $10 \mathrm{~kg}_{\mathrm{CS}} / \mathrm{t}$. The ash contents of the filled sheets were ca. $15 \%$. The $200 \mu \mathrm{m}$ scale bar applies to the micrographs marked with

SEM images (Fig. 7c) suggest that bonding of MFC was poor when PCC-CTMP was used, which was the probable reason for its poor performance. The PCC appeared to reside on the MFC fibrils, even though the MFC was added to the furnish after the PCC precipitation.

This, combined with the lack of CTMP fibres free from PCC in the samples filled using PCC-CTMP, suggests that the free PCC had an affinity for fibrous surfaces. This may have been due to a charge in the particles. Korhonen and Laine (2014) reported for the flocculation of cationic PCC and nanocellulose without any retention aid, but in our case, the charge was

letters only, and the $50 \mu \mathrm{m}$ scale bar applies all close-ups (indicated with letter and a number). The grey bars in the middle represent the bulk of the sheet; the thickness corresponding $320 \mu \mathrm{m}$ was removed from each micrograph. The wire side is facing upwards

not investigated. The loss of mineral-free surface area was, however, also associated with the poor bonding of the cellulosic species in the MFC-reinforced sheets.

According to the literature, the higher the filler content of the sheet, the higher the strength improvement that can be achieved using cationic starch (Lindström and Florén 1987; Lindström et al. 2005). The improvement is often explained by hydrogenbonding of the starch to the filler surface, or within the filler structure, and ability of the filler to bond with the fibres (He et al. 2016; Li et al. 2016). This may have taken place, but the magnitude of the improvement was surprising because the CTMP\&PCC-CTMP(CS) 

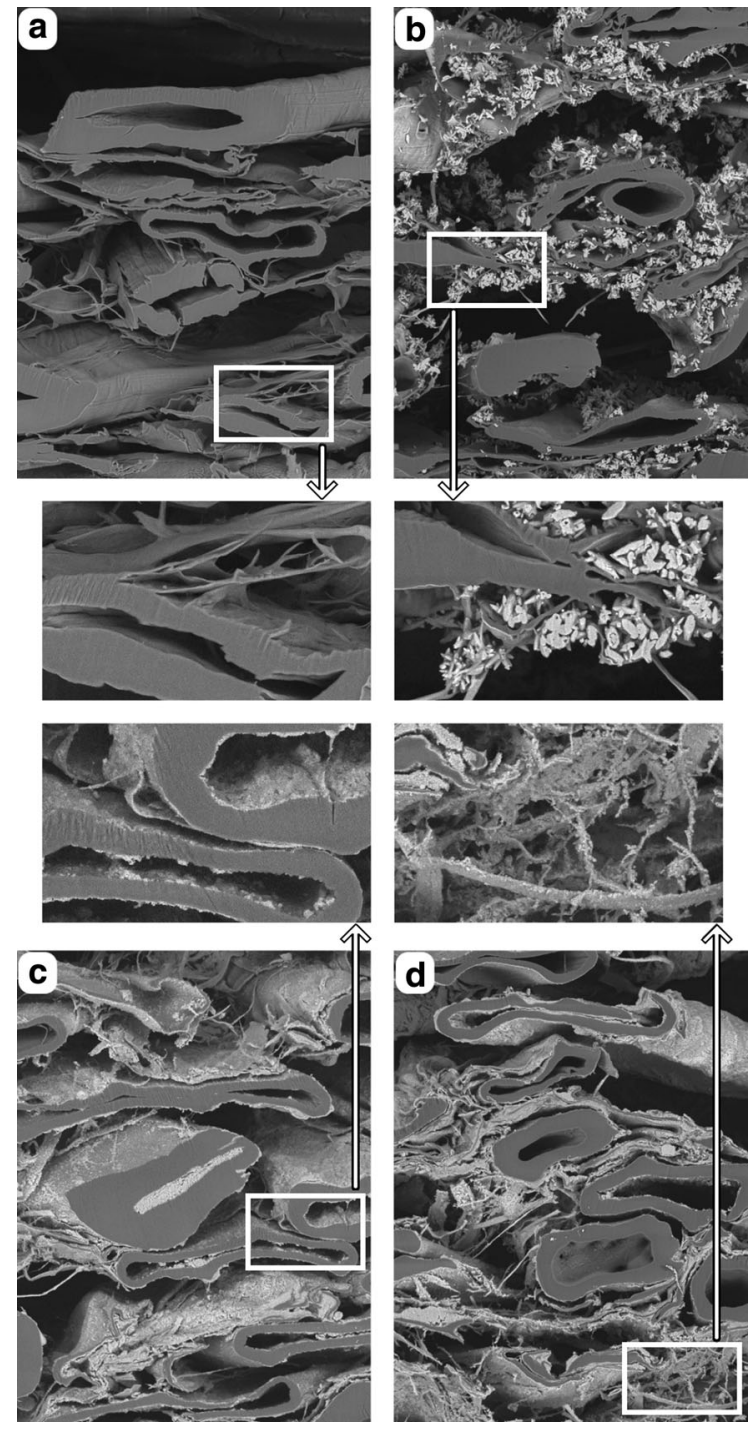

Fig. 8 SEM micrographs of the samples: a CTMP: reference sample b CTMP\&PCC(CS)starch, $12 \quad \mathrm{~kg}_{\mathrm{CS}} / \mathrm{t}$ c CTMP\&PCCCTMP without a strengthening agent d CTMP\&PCCCTMP(MFC), $13 \mathrm{~kg}_{\mathrm{MFC}} / \mathrm{t}$. The ash contents of filled sheets were ca. $15 \%$. The $25 \mu \mathrm{m}$ scale bar applies to all micrographs marked with letters, and the $5 \mu \mathrm{m}$ scale bar applies to the closeups. The wire side is facing upwards

sheets were significantly stronger than the CTMP\&PCC(CS) sheets, and some of the properties improved with increasing ash content, although the amount of starch was the same. This suggests that the mineral played a more active role in creating sheet strength, perhaps because aggregates of nano-PCC attached to CTMP fines were able to function as bondforming material between the fibres, due to the starch

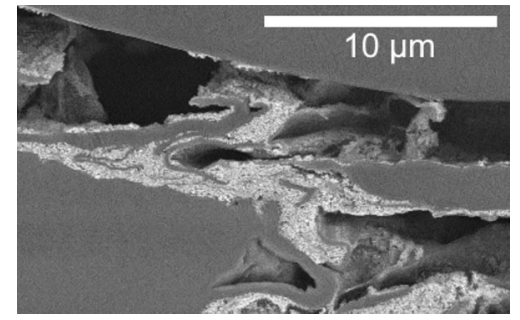

Fig. 9 A bridge of PCC and perhaps cellulosic fines between two CTMP fines in CTMP\&PCC-CTMP(CS), $12 \mathrm{~kg}_{\mathrm{Cs}} / \mathrm{t}$. The ash content was $15.8 \%$

on the mineral surfaces. In the traditionally filled sheets, the surface area of PCC was smaller (based on the SEM micrographs), and the load-bearing ability of the looser aggregates was less. The SEM micrographs of the CTMP\&PCC-CTMP(CS) sheets (Fig. 9) support the hypothesis that $\mathrm{PCC}$-rich, bridge-like areas exist between the fibres, although it is not clear from the images whether these structures are able to bear any load.

\section{D elongation and load-elongation curve}

\section{Elastic modulus, tensile stiffness and bending stiffness}

Many of the strength properties found to correlate with extensibility are defined in a manner that they share a physical component, ratio of applied tensile force and elongation $(\Delta F / \Delta \delta)$. Elastic modulus, reported to correlate with $3 \mathrm{D}$ elongation, is defined as "tensile stiffness divided by thickness" under the standard ISO 1924-3. The same standard ISO 1924-3 defines tensile stiffness as "maximum slope of the curve obtained when tensile force per unit width is plotted versus strain", and that it can be calculated using the equation

$E^{b}=\frac{\Delta F}{\Delta \delta} \cdot \frac{l}{b}$

where $F$ is force, $\delta$ elongation, $l$ is the initial length and $b$ the initial width of the test piece. Also, bending stiffness is linked with the $\Delta F / \Delta \delta$ due to its link with elastic modulus (prediction with $S_{b}=\int E(z) z^{2} \mathrm{~d} z$ (Kajanto 1998)).

Since the applied pressure in forming alters the sample thickness and thus elastic modulus, and the load is borne by the solid components in the sheets (Page et al. 1979), it could be better to calculate the 
specific modulus of elasticity, $E / \rho$, for attempting to predict the $3 \mathrm{D}$ elongation.

$\frac{E}{\rho}=\frac{\frac{\Delta F}{\Delta \delta} \cdot \frac{l}{b t}}{\rho}=\frac{\Delta F}{\Delta \delta} \cdot \frac{l}{b w}$

in which $\rho$ is the initial density of the test piece and $w$ is the grammage of the sheet. In our data, the coefficient of determination $R^{2}$ for $3 \mathrm{D}$ elongation versus specific modulus of elasticity was higher than that for 3D elongation versus elastic modulus $(0.59$ and 0.50 , respectively). When the tensile stiffness was correlated with the 3D elongation, the $R^{2}$ value for the relationship between 3D elongation and tensile stiffness, shown in Fig. 5, was 0.61.

The $R^{2}$ value for the relationship between $3 \mathrm{D}$ elongation and bending stiffness was 0.52 . For nonlayered sheets, the bending stiffness can be calculated using

$S_{b}=E d^{3} / 12$

(Kajanto 1998), and the calculated values were found to be in good agreement with the measured values. Both the elastic modulus and the bending stiffness thus depended on the ratio $\Delta F / \Delta \delta$ and sheet thickness. Although this study did not show a good correlation between 3D elongation and bending stiffness, its role should be further clarified using layered sheets with a controlled structure and composition in order better to distinguish bending stiffness and the $\Delta F / \Delta \delta$ ratio based on tensile stretching.

\section{Tensile strength and bursting strength}

When the coefficient of determination, $R^{2}$, for $3 \mathrm{D}$ elongation versus a correlating property (tensile stiffness, elastic modulus, bending stiffness, tensile strength or bursting strength) was determined, the highest $R^{2}$ value (0.68) was for 3D elongation versus tensile strength, followed by $R^{2}$ value $3 \mathrm{D}$ elongation versus bursting strength (0.67).

Bursting strength correlated well with the tensile strength $\left(R^{2}\right.$ value of tensile strength versus bursting strength was 0.96). The correlation between tensile strength and bursting strength is typical because they are affected by the same fibre properties (Wistara and Young 1999), and bursting strength can be calculated using the product of tensile strength and square root of sheet stretch (Seth 2005). The correlation and burst test geometry that resembles fixed blank forming geometry make the bursting strength a property of interest when searching for correlations between 3D elongation and a results of standardised laboratory tests. A method with similarity to the standard bursting strength test, pneumatic bulge test (PBG), has also been developed and applied to characterise stretching (Huttel et al. 2011; Groche et al. 2012).

The positive correlation between $3 \mathrm{D}$ elongation and tensile strength is explained by improved distribution of tensile stress in the sheet, and the improved utilisation of fibre straining potential (Vishtal 2015). Retulainen (1996) suggests that with a given set of fibres at a given grammage, the tensile strength can be altered by changing the bonding. The tensile strength can also be affected by the fibre network structure and therefore by, e.g., restrained drying, but in our CTMP sheets, it can be assumed that tensile strength depended mainly on the bonding.

Tensile stiffness and tensile strength in assessing $3 D$ elongation

In the context of 2D stretching, Seth (2005) introduced the concept of the stretch-potential of fibres and explained that in order to realise the potential, sufficient bonding is required, and this was confirmed by Kouko et al. (2020). We suggest that in the context of $3 \mathrm{D}$ elongation, the observed results may also be explained in the same manner. Tensile strength in many cases is probably indicative of the bonding and stress distribution within the sheet, while the role of the " $\Delta F / \Delta \delta$ dependent" parameters, i.e. elastic modulus, tensile stiffness, and perhaps bending stiffness, is probably more complex.

We suggest that in bulky and somewhat poorly bonded sheets, such as the CTMP sheets, the 3D elongation is strongly dominated by the bonding, which explains the strong correlation between 3D elongation and tensile strength. The elastic modulus, tensile stiffness and perhaps bending stiffness probably show a positive correlation with $3 \mathrm{D}$ elongation because the specific elastic modulus increases with increasing bonding until it reaches a plateau, unless the fibre elasticity is simultaneously affected (Seth and Page 1981).

In more strongly bonded sheets, we expect to see a weaker correlation between tensile stress and 3D elongation, as the increase in sheet bonding allows a 
greater realisation of the elongation potential of the fibres and of the fibre web structure. Simultaneously a negative correlation between tensile stiffness and 3D elongation is expected, due to an unrestrained sheet drying and the presence of microcompressions and crimps in the fibres (Vishtal 2015), which increases the extensibility in press forming while negatively affecting the tensile stiffness (Vishtal 2015) and specific elastic modulus (Page and Seth 1980b).

This hypothesis is in agreement with the work of Page et al. (1979), who described two mechanisms that affect the specific elastic modulus, improved stressdistribution resulting from an increase in bonding (controlling the elastic modulus of the less bonded sheets), and by the elastic properties of fibres (affected, for example, by the presence of crimps and stresses in the fibres), which control the plateau level of specific elastic modulus.

This would explain why the heat and moisture during the press-formation generally improve the extensibility, despite the decreasing elastic modulus and the observed correlation between the $3 \mathrm{D}$ elongation and elastic modulus being the opposite. The plasticisation of the fibre polymers caused by heat and moisture affects fibres in a manner that improves their stretch potential under given bonding, although the bond strength is also affected by the moisture content (Salmén 1993). Therefore, it is expected that if the moisture content is increased further, the 3D elongation is reduced when the negative effects on sheet bonding exceed the positive effects on plasticisation. Tanninen et al. (2017a) have reported a decrease in formability with high moisture contents, and Salmén (1993) describes the softening of wood polymers with heat and moisture, especially the decrease in elastic modulus and the loosening of bonds due to the presence of moisture.

To summarise, we suggest that the correlation between $3 \mathrm{D}$ elongation and tensile strength (and thus burst strength) results from increased bonding of the sheet, while the correlation between 3D elongation and tensile stiffness, elastic modulus and, perhaps, bending stiffness is more complex originating at the fibre and sheet level, the dominating factor in the generation of sheet elongation depending on whether the bonding allows the elongation potential of the fibre to be realised. This stresses the importance of understanding the origin of each property correlating with the $3 \mathrm{D}$ elongation.

\section{Conclusions}

In this work, we studied the 3D elongation and strength of CTMP-based sheets filled with PCC added as a slurry to the furnish or precipitated onto the fibre surfaces often as nano-sized particles. MFC or cationic starch were added as dry-strengthening agents. The 3D elongation correlated positively with the tensile strength and bursting strength (affected by the same fibre properties, and tensile strength often being associated with the bond strength), and with tensile stiffness, elastic modulus and bending stiffness, all of which are related to the ratio of applied tensile force and elongation $(\Delta \mathrm{F} / \Delta \delta)$ in a tensile test via the formulae of paper physics. No significant correlations were observed with the 3D elongation and other measured physical properties of the sheets. Despite the use of the two morphologically different PCC fillers and the two chemically different strengthening aids, no evidence on the effect of filling or strengthening aids on 3D elongation were observed beyond those related to the strength properties, despite their hypothesised effects on friction and thermal conductivity of the sheet and thus, the possibility for improved plasticisation.

The method of mineral filling affected the effectiveness of the strengthening agents: MFC performed poorly on PCC-CTMP filled sheets, but cationic starch performed better on PCC-CTMP and some strength properties increased with increasing ash content even at a constant level of adsorbed starch. The difference was attributed to a decrease in mineral-free surface area of the fibre and a resulting loss of bonding (MFC) and of the active role of the mineral in sheet bonding (cationic starch). However, no obvious correlation between $3 \mathrm{D}$ elongation and ash content took place, despite the theorised benefits of presence of filler in forming.

Acknowledgments Stora Enso Oyj is acknowledged for financial support of the project. Dr. Anthony Bristow is thanked for linguistic revision of the manuscript. Mr. Antti Pesonen and Dr. Panu Tanninen are thanked for their help in running the press-forming trials. The staff of Stora Enso Research Centre Imatra is gratefully acknowledged for participation in assessing the physical properties of the handsheets.

Open Access This article is licensed under a Creative Commons Attribution 4.0 International License, which permits use, sharing, adaptation, distribution and reproduction in any 
medium or format, as long as you give appropriate credit to the original author(s) and the source, provide a link to the Creative Commons licence, and indicate if changes were made. The images or other third party material in this article are included in the article's Creative Commons licence, unless indicated otherwise in a credit line to the material. If material is not included in the article's Creative Commons licence and your intended use is not permitted by statutory regulation or exceeds the permitted use, you will need to obtain permission directly from the copyright holder. To view a copy of this licence, visit http://creativecommons.org/licenses/by/4.0/.

Funding Open access funding provided by LUT University (previously Lappeenranta University of Technology (LUT)).

\section{References}

Groche P, Huttel D, Post P-P, Schabel S (2012) Experimental and numerical investigation of the hydroforming behavior of paperboard. Prod Eng Res Devel 6:229-236. https://doi. org/10.1007/s11740-012-0365-y

He M, Cho B-U, Won JM (2016) Effect of precipitated calcium carbonate-Cellulose nanofibrils composite filler on paper properties. Carbohyd Polym 136:820-825. https://doi.org/ 10.1016/j.carbpol.2015.09.069

Hubbe, M.A, Filler Particle Shape vs. Paper Properties-A Review, TAPPI 2004 Spring Tech Conference, Altlanta, Paper 7-3

Hubbe MA, Gill RA (2016) Fillers for papermaking: a review of their properties, usage practices, and their mechanistic role. BioRes 11(1):2886-2963

Huttel D, Post P, Schabel S, Groche P (2011) The stress strain behaviour of paperboard in tensile and bulge tests. In Proceedings of the 10th International Conference on Technology of Plasticity, ICTP 2011 (G. Hirt, Tekkaya E.A, eds.), Aachen, Germany, pp 811-816, 2011.

Ihrman C.B, Öhrn, O.E (1965) Extensible paper by the doubleroll compacting process. In Consolidation of the Paper Web. Trans. 3rd Fund. Res. Symp. (F. Bolam, ed.), pp 410-434, Cambridge, U.K., 1965.

Jahangir ES, Olson JA (2020) Low consistency refined lignocellulose microfibre: an MFC alternative for high bulk, tear and tensile mechanical pulp papers. Cellulose 2020(27):2803-2816. https://doi.org/10.1007/s10570-01902956-2

Kajanto I (1998) Fibers and bond. In: Niskanen K (ed) Papermaking science and technology vol. 16, Paper physics, Fapet Oy, Jyväskylä, pp. 193-221

Kajanto I (2003) Paper physicist's point of view to moulding of paperboard trays. In Annual traystorming seminar, Düsseldorf Germany

Kajanto I, Kosonen M (2012) The potential use of micro- and nano-fibrillated cellulose as a reinforcing element in paper. J-FOR 2(6):42-48

Koivunen K, Niskanen I, Peiponen K-E, Paulapuro H (2009) Novel nanostructured PCC fillers. J Mater Sci 44:477-482. https://doi.org/10.1007/s10853-008-3095-y
Korhonen J, Laine J (2014) Flocculation and retention of fillers with nanocelluloses. Nord Pulp Pap Res j 29(1):119-128. https://doi.org/10.3183/npprj-2014-29-01-p119-128

Koskenhely K (2008) Refining of chemical pulp fibers. In: Paulapuro H (ed) Papermaking science and technology vol. 8, Papermaking Part 1: Stock Preparation and Wet End, Fapet Oy, Jyväskylä, pp. 94-139

Kouko J, Turpeinen T, Kulachenko A, Hirn U, Retulainen E (2020) Understanding extensibility of paper: role of fiber elongation and fiber bonding. Tappi J 19(3):125-135

Krogerus B (2007) Papermaking additives. In: Alén R (ed) Papermaking science and technology vol. 4, 2nd ed., Fapet Oy, Jyväskylä, pp. 56-126

Kuusisto J, Maloney TC (2016) Preparation and characterization of corn starch-calcium carbonate hybrid pigments. Ind Crop Prod 83:294-300. https://doi.org/10.1016/j.indcrop. 2016.01.026

Laukala T, Ovaska S, Tanninen P, Pesonen A, Jordan J, Backfolk K (2019) Influence of pulp type on the three-dimensional thermomechanical convertibility of paperboard. Cellulose 26:3455-3471. https://doi.org/10.1007/s10570019-02294-3

Leminen V, Tanninen P, Lindell H, Varis J (2015) Effect of Blank Holding Force on the Gas Tightness of Paperboard Trays Manufactured by the Press Forming Process. BioRes 10(2):2235-2243. https://doi.org/10.15376/biores.10.2. 2235-2243

Li T, Fan J, Chen W, Shu J, Qian X, Wei H, Wang Q, Shen J (2016) Coaggregation of mineral filler particles and starch granules as a basis for improving filler-fiber interaction in paper production. Carbohyd Polym 149:20-27. https://doi. org/10.1016/j.carbpol.2016.04.082

Lenske A, Müller T, Penter L, Schneider M, Hauptmann M, Majschak JP (2017) Evaluating the factors influencing the friction behavior of paperboard during the deep drawing process. BioRes 12(4):8340-8358

Lindström T, Florén T (1987) The effect of filler particle size and the dry-strengthening effect of cationic starch wet-end addition. Nord Pulp Pap Res j 2(4):142-145. https://doi. org/10.3183/npprj-1987-02-04-p142-145

Lindström T, Wågberg L, Larsson T (2005) On the nature of joint strength in paper - A review of dry and wet strength resins in paper manufacturing. In: Advances in Paper Science and Technology, Trans. of the XIIIth Fund. Res. Symp. Cambridge (S.J. I'Anson, ed.), pp 457-562, FRC, Manchester, 2018. https://doi.org/10.15376/frc.2005.1.457

Ostlund S (2017) Three-dimensional deformation and damage mechanisms in forming of advanced structures in paper. In: Advances in Pulp and Paper Research, Oxford 2017, Trans. of the XVIth Fund. Res. Symp. Oxford, 2017, (W. Batchelor and D. Söderberg, eds), pp 489-594, FRC, Manchester, 2018.

Page DH (1969) A theory for the tensile strength of paper. Tappi J 52(4):674-681

Page DH, Seth RS (1980a) The elastic modulus of paper II. The importance of fiber modulus, bonding and fiber length. Tappi J 63(6):113-116

Page DH, Seth RS (1980b) The elastic modulus of paper III The effects of dislocations, microcompressions, curl, crimps and kinks. Tappi J 63(10):100-102 
Page DH, Seth RS, De Grace JH (1979) The elastic modulus of paper I. The Controlling Mechanisms. Tappi J 62(9):99-102

Retulainen E (1996) Fibre properties as control variables in papermakin? Part 1. Fibre properties of key importance in the network. Pap Puu 78(4):187-194

Salmén L (1993) Responses of paper properties to changes in moisture content and temperature. In: Products of Papermaking, Trans. of the Xth Fund. Res. Symp. Oxford, 1993, (C.F. Baker, ed.), pp 369-430, FRC, Manchester, 2018.

Shen J, Song Z, Qian X, Liu W (2009) Modification of papermaking grade fillers: a brief review. BioRes 4(3):1190-1209

Seth RS (2005) Understanding sheet extensibility. Pulp PapCanada 106(2):33-38

Seth, R.S., Page D.H. (1981) The stress strain curve of paper, In: J Brander (ed) The Role of Fundamental Research in Paper Making, Trans. VIIth Fund. Res. Symp. Cambridge, pp 421-452.

Silenius P (2002) Improving the combinations of critical properties and process parameters of printing and writing papers and paperboards by new paper-filling methods. Dissertation, Helsinki University of Technology

Tanninen P, Leminen V, Eskelinen H, Lindell H, Varis J (2015) Controlling the Folding of the Blank in Paperboard Tray Press Forming. BioRes 10(3):5191-5202. https://doi.org/ 10.15376/biores.10.3.5191-5202
Tanninen P, Matthews S, Ovaska S-S, Varis J, Backfolk K (2017a) A novel technique for the evaluation of paperboard performance in press-forming. J Mater Process Technol 240:284-292. https://doi.org/10.1016/j.jmatprotec.2016. 10.002

Tanninen P, Ovaska S-S, Matthews S, Mielonen K, Backfolk K (2017b) Utilization of production-scale machine in experimental fiber material convertibility test using a novel press forming tool set. BioRes 12(1):3030-3042

Vishtal A (2015) Formability of paper and its improvement. Dissertation, Tampere University of Technology

Vishtal A, Retulainen E (2014a) An approach for improved 3D formability of paper. IPW 12:46-50

Vishtal A, Retulainen E (2014b) Boosting the extensibility potential of fibre networks: a review. BioRes 9(4):7951-8001. https://doi.org/10.15376/biores.9.4.79518001

Wistara N, Young RA (1999) Properties and treatments of pulps from recycled paper. Part I. Physical and chemical properties of pulps. Cellulose 6:291-324. https://doi.org/10. 1023/A:1009221125962

Publisher's Note Springer Nature remains neutral with regard to jurisdictional claims in published maps and institutional affiliations. 